\title{
Romantic Relationships as Shared Reality Defense
}

\author{
Sandra L. Murray* \\ University at Buffalo, State University of New York \\ Veronica Lamarche \\ University of Essex \\ Mark D. Seery \\ University at Buffalo, State University of New York
}

*Corresponding author. Sandra Murray, Psychology Department, University at Buffalo, State University of New York, Buffalo, NY, 14620-4110. Email: smurray@buffalo.edu. 


\begin{abstract}
A model of meaning maintenance in relationships is proposed to explain how relationships function to regulate threats to shared systems of meaning posed by life's capricious and unexpected events. This model assumes that people flexibility compensate for unexpected events in the world by affirming the expected in their relationship and compensate for unexpected events in the relationship by affirming the expected in the world. Supportive evidence is reviewed that reveals how people in more or less satisfying relationships flexibly maintain a sense of life's meaning in the face of unexpected events.
\end{abstract}


Reality is nothing but a collective hunch.

\section{Lily Tomlin, "The Search for Signs of Intelligent Life in the Universe"}

For people to engage in goal-directed action, life needs to make sense, with events unfolding as expected. However, life rarely unfolds just as people expect $[1,2,3,4,5,6,7,8]$. The stock market can rise when it should fall, the diligent can fail while the profligate prosper, the incompetent can take political power, and trusted romantic partners can be impulsive and unpredictable. Because goal directed action depends on the perception of the expected, the perception of the unexpected motivates people to find expedient and effective ways to affirm that the meaning, order, and stability they expect to see in the world does indeed exist $[1,2,3,4]$.

In shared reality theory, interactions with others afford a primary means of defending against unexpected events because such interactions afford a means for people to reaffirm the meaning and order they expect to see in the world $[9,10,11]$. Romantic relationships likely provide an especially powerful context for defending and validating such collective hunches about how the world works inside and outside the relationship. Romantic partners are interdependent across multiple diverse domains, including the negotiation of household roles, desires for intimacy, and the merging of political values and religious traditions [12, 13]. Given such breadth of interdependence, romantic relationships offer multiple opportunities for both affirming and violating shared expectations about how the world inside and outside the relationship works $[14,15]$.

Specifically, when events outside the relationship violate shared understandings of how the world works, people could flexibly compensate for such worldly disorder by affirming the meaning and order they expect to see inside their relationship. When Arya's hard work comes to naught and an undeserving colleague is promoted over her, she could defensively assert the 
presence of expected meaning in her life by affirming the strength of her commitment to her spouse Aaron [16]. In this way, imposing order on the relationship could function as a palliative salve for the unexpected in the world. Conversely, when events inside the relationship violate shared understandings of how the relationship works, people could flexibly compensate for such relationship disorder by affirming the meaning and order they expect in the world outside the relationship. When Aaron confounds Arya's expectations and takes up a new high adrenaline sport, affirming culturally shared beliefs that every cloud has a silver lining can help reassert the presence of meaning and order in her world [17]. In this way, imposing order on the world could function as a palliative salve against the unexpected in the relationship.

Building on these ideas, Figure 1 models how relationships function to regulate threats to shared systems of meaning posed by life's capricious and unexpected events. This model assumes that people have greater confidence in shared realities, and thus, experience a greater sense of meaning and purpose in life, when both their romantic relationship (Path A) and broader world (Path B) make sense and behave as they expect. But, capricious relationship and world events can confound expectations fairly routinely. Therefore, this model also assumes that people need the capacity to compensate, flexibly substituting the threatened source of meaning for the alternate source of meaning to preserve confidence in the shared realities that afford a sense of meaning and purpose in life, just as Arya and Aaron did in the examples above.

This model further assumes that the motivation to make such compensatory shifts depends on the chronic centrality of the threatened domain to people's overall sense of life purpose. Romantic relationships differ in how much they can contribute to a sense of meaning and purpose in life because they vary in quality. People who are high in satisfaction inhabit relationships that largely meet their expectations, whereas people who are low in satisfaction 
inhabit relationships that largely fall short of their expectations $[11,15,16]$. Being involved in a more satisfying relationship is inherently more sensible, consonant, and ordered than being involved in a less satisfying relationship. Therefore, people in more satisfying relationships can draw more of their life's meaning from their relationship than people in less satisfying ones [16].

Consequently, when events in the relationship violate expectations, such events should pose a greater threat to life's meaning for people who are more satisfied in their relationship (because they depend more on perceiving order in their relationship for a sense of meaning in life than less satisfied people). Therefore, when the unexpected happens in the relationship, more satisfied people should be more likely to flexibly compensate for this threat to relationship order by affirming the presence of the expected in the world than less satisfied people (Path $\mathrm{C}$ in Figure 1). However, when events in the world violate expectations, such events should pose a greater threat to people who are less satisfied in their relationship (because they depend more on perceiving order in the world for a sense of meaning in their life than more satisfied people). Therefore, when the unexpected happens in the world, less satisfied people should be more likely to flexibly compensate for this threat to world order by affirming the presence of the expected in the relationship than more satisfied people (Path D in Figure 1).

\section{Relationships Function as Shared Reality Defense}

We first review evidence that less satisfied people compensate for the unexpected in the world by imposing greater order on the relationship. Then, we review evidence that more satisfied people compensate for the unexpected in the relationship by imposing greater order on the world.

\section{Compensating for Threats to World Order}

To test whether people in less satisfying relationships compensate for threats to meaning 
and order in the world by imposing greater order on their relationship, we captured people in the moment(s) of having their beliefs about how the world works shaken. We did this using three different, but convergent methodological approaches [16, 17].

First, in a set of five experiments, we violated consensual knowledge about how the world works by exposing experimental participants to unconventional or unexpected stories, images, or phenomenological experiences and control participants to conventional ones [16]. For instance, in two of these studies, experimental participants read an expectancy violating, unconventional story about a messenger who perseveres and successively overcomes a series of obstacles and travails, only to ultimately fail in his intended quest to deliver a message to his king, while control participants read an expectancy-affirming conventional story where perseverance and hard work pays off. Second, in a daily diary, we asked participants to indicate each day whether (or not) they had seen anything absurd or ridiculous in the news, anything in the media that disturbed or shocked them, or anything in the media that made no sense to them on the assumption that events that violated expectations about the world would seem absurd, disturbing, and/or shocking [17]. Third, in a longitudinal study of the transition to first parenthood, we identified parenting experiences likely to violate conventional assumptions about the allocation of household chores [16]. In Western culture, women typically expect and take more domestic responsibility than men once they become parents [18]. Such clear cultural norms make it possible to identify people whose post-baby experiences violate such gendered expectations for the division of labor. Namely, new mothers whose pre-baby expectations overestimated their post-baby responsibilities (i.e., mothers who expected to do more) and new fathers whose pre-baby expectations underestimated their post-baby responsibilities (i.e., fathers 
who expected to do less) had culturally shared and endorsed personal expectations about the conventional domestic order violated over the transition to parenthood.

In each of these research paradigms, we then had to decide how to assess our primary dependent measure, the affirmation of the expected on the relationship. Across studies, we captured such a compensatory affirmation of relationship order through commitment.

Commitment is an approach-oriented or purpose-driven relationship sentiment that captures the intention to maintain the relationship through good times and bad [19]. Indeed, commitment imbues action with such a resolute sense of meaning and purpose that strong commitments automatically motivate people to put caring for their partner ahead of pursuing self-interested temptations [20]. Feeling committed essentially sets the relationship "right" because people have a fundamental need to believe they are in fact in the right relationship with the right person.

When the unexpected happens in the world, less satisfied people across these studies flexibly compensated for threats to world order by affirming the presence of the expected in the relationship. When we experimentally violated expectations about the world, less satisfied people defensively affirmed their commitment to their partner; in fact, less satisfied people in the expectancy violation conditions reported just as strong and certain commitments to their partner as highly satisfied people [16]. In the daily study, less satisfied people also compensated for absurdity-filled news days by expressing even greater commitment to their partner the next day [17]. And across the transition to parenthood, less satisfied new mothers who overestimated their responsibilities (i.e., violating the cultural expectation that women should do more) and less satisfied new fathers who underestimated their responsibilities (i.e., violating the cultural expectation that men should do less) increased commitment from pre- to post-baby [16]. 


\section{Compensating for Threats to Relationship Order}

To test whether people in more satisfying relationships compensate for threats to meaning and order inside the relationship by imposing greater order on the world outside the relationship, we captured people in the moment(s) of having their beliefs about how their relationship works shaken. In a daily diary study, we asked participants to report each day whether (or not) their partner had done anything - good or bad - out of the ordinary, unexpected, or that did not make any sense. We also asked them to report whether or not their partner had engaged in any hurtful, rejecting, or interfering behaviors (enabling us to separate violations of shared expectations for how the relationship works from partner bad acts). To capture the imposition of order on the world outside the relationship, we captured the strength of participants' daily belief in cultural truisms, such as "hard work pays off”, "a job worth doing is worth doing well”, "cheaters never prosper", and "good things come to those who wait".

When the unexpected happens in the relationship, more satisfied people in this daily diary study flexibly compensated for threats to order within their romantic relationship by affirming the presence of the expected in the world outside the relationship [17]. That is, more satisfied people compensated for days when their partner behaved in more expectancy-violating, unpredictable, and inexplicable ways by believing all the more in the veracity of cultural truisms the next day. However, less satisfied people did not compensate for their partner's rejecting and hurtful behavior by clinging to cultural truisms, presumably because a partner's daily negative behavior, while unpleasant, is not necessarily unexpected. Moreover, clinging to the veracity of cultural truisms in the face of a partner's unexpected behavior seemed to ameliorate this threat to confidence in life's meaning and purpose. When more satisfied people flexibly affirmed cultural 
truisms in the face of their romantic partner's unexpected behaviors, they reported feeling more certain of their life's meaning and purpose the next day.

\section{Conclusion}

Unexpected events can leave people in need of a reality check. When the world turns upside-down, relationships offer a means of reestablishing meaning and order. But relationships can also be a source of disorder and confusion, motivating people to reaffirm collective hunches about the world. Thus, romantic relationships are central to the defense of shared realities. 


\section{References}

1. Harmon-Jones, E., Amodio, D. M., \& Harmon-Jones, C. (2009). Action-based model of dissonance: A review, integration, and expansion of conceptions of cognitive conflict. In J. Olson \& M. P. Zanna (Eds.), Advances in experimental social psychology, 41, 119166.

2. Harmon-Jones, E., Harmon-Jones, C., \& Levy, N. (2015). An action-based model of cognitive dissonance processes. Current Directions in Psychological Science, 24, 184189.

3. Heine, S. J., Proulx, T., \& Vohs, V. (2006). The meaning maintenance model: On the coherence of social motivations. Personality and Social Psychology Review, 10, 88-110.

*4. Jonas, E., McGregor, I., Klack1, J., Agroskin, D., Fritsche, I., Holbrook, C., Nash, K., Proulx, T., \& Quirin, M. (2014). Threat and defense: From anxiety to approach. In J. M. Olson \& M. P. Zanna (Eds.), Advances in Experimental Social Psychology (pp. 219-286). Elsevier Inc. Integrative discussion of how expectancy violations simultaneously induce anxiety and motivate compensatory approach motivation.

5. Sleegers, W., \& Proulx, T. (2015). The comfort of approach: Self-soothing effects of behavioral approach in response to meaning violations. Frontiers in Psychology, 5, 1568.

6. McGregor, I., Prentice, M., \& Nash, K. (2012). Approaching relief: Compensatory ideals relieve threat-induced anxiety by promoting approach-motivated states. Social Cognition, 30, 689-714.

7. Holbrook, C. (2016). Branches of a twisting tree: Domain-specific threat psychologies derive from shared mechanisms. Current Opinion in Psychology, 7, 81-86. 
8. Landau, M. J., Kay, A., C., \& Whitson, J. A. (2015). Compensatory control and the appeal of a structured world. Psychological Bulletin, 141, 694-722.

9. Hardin, D. D., \& Higgins, E. T. (1996). Shared reality: How social verification makes the subjective objective. In M. R. Sorrentino \& E. T. Higgins (Eds.), Handbook of motivation and cognition (Vol. 3, pp. 28-84). NY: Guilford Press.

10. Echterhoff, G., Higgins, E. T., \& Levine, J. M. (2009). Shared reality: Experiencing commonality with others' inner states about the world. Perspectives on Psychological Science, 4, 496-521.

11. Echterhoff, G., Kopietz, R., \& Higgins, E. T. (2013). Adjusting shared reality:

Communicators' memory changes as their connection with their audience changes. Social Cognition, 31, 162-186.

12. Kelley, H. H. (1979). Personal relationships: Their structures and processes. Hillsdale, NJ: Erlbaum.

13. Baumeister, R. F., \& Leary, M. R. (1995). The need to belong: Desire for interpersonal attachments as a fundamental human motivation. Psychological Bulletin, 117, 497-529.

14. Fitzsimons, G. M., Finkel, E. J., \& Vandellen, M. R. (2015). Transactive goal dynamics. Psychological Review, 122, 648-673.

15. Lemay, E. P., Jr., \& Venaglia, R. B. (2016). Relationship expectations and relationship quality. Review of General Psychology, 20, 57-70.

**16. Murray, S. L., Lamarche, V., Gomillion, S., Seery, M. D., \& Kondrak, C. (2017). In defense of commitment: The curative power of violated expectations. Journal of Personality and Social Psychology, 113, 697-729. 
Discusses how people use their relationships to compensate for the unexpected events. Reveals that less satisfied people affirm commitment in the face of violations.

17. Murray, S. L., Lamarche, V., \& Seery, M. D. Relationships as meaning defense. Unpublished raw data.

18. Lachance-Grzela, M., \& Bouchard, G. (2010). Why do women do the lion's share of housework? A decade of research. Sex Roles, 63, 767-780.

19. Rusbult, C. E., Martz, J. M., \& Agnew, C. R. (1998). The investment model scale: Measuring commitment level, satisfaction level, quality of alternatives, and investment size. Personal Relationships, 5, 357-391.

20. Slotter, E. B., Finkel, E. J., DeWall, C. N., Lambert, N. M., Pond, R. S., Bodenhausen, G. V., \& Fincham, F. D. (2012). Putting the brakes on aggression toward a romantic partner: The inhibitory influence of relationship commitment. Journal of Personality and Social Psychology, 102, 291-305. 


\section{Authors' Notes}

Address correspondence to Sandra Murray, Department of Psychology, Park Hall, University at Buffalo, The State University of New York, Buffalo, NY, 14260-4110. E-mail:

smurray@buffalo.edu. The preparation of this paper was supported by a grant from the National Science Foundation (BCS-1143747) to S. L. Murray and M. D. Seery. 